\title{
Los derechos culturales o la culturalización de los derechos de los pueblos indígenas
}

\author{
Mariana del Rocío Aguilar Bobadilla \\ Universidad Pedagógica Nacional/Facultad de Estudios Superiores Aragón, \\ UNAM
}

Introducción

Más que la verdad disponible se presenta la actitud ante los criterios de la modernidad cientifica y ante la tolerancia instalada (...) exhibe el apego de una mayoría social a los criterios tradicionales todavía operantes. El fundamentalismo, declaración de resistir lo que se pueda a la modernidad. (...)

Al mismo tiempo, es innegable el avance de la tolerancia, una de las señales inequívocas del poder de la secularización. Las minorías se organizan, marchan a varias ciudades, le exigen a las autoridades de salud, trascienden el prejuicio con la exigencia de sus derechos, desafían el racismo. Más allá de las encuestas, útiles pero nunca definitivas, se despliega el avance de la sociedad. (Carlos Monsiváis ${ }^{1}$ )

El escenario mundial en las últimas tres décadas evidenció cambios sustanciales en todos los órdenes junto con los estragos de una larga crisis tendiente a agudizarse y hacerse permanente, en América Latina de manera particular, a esta situación se sumó la ausencia de un proyecto de Estado que hiciera frente a los problemas derivados de este contexto. Los períodos de crisis se asocian con movilizaciones sociales y populares con demandas económicas y por la democratización, sin embargo, en este período se sumaron movimientos sociales emergentes: étnicos, de género, ecologistas, ambientalistas, contra la violencia, por la diversidad sexual, por los derechos humanos, etc., como consecuencia de las tensiones generadas en el seno de las sociedades 'totales' que excluyeron toda consideración cultural en la determinación de 
la condición ciudadana ${ }^{2}$. Esta crisis exhibe: 1) la capacidad de movilización y organización política de nuevos actores sociales para posicionarse en los espacios públicos, lograr interlocución con el Estado e incidir en las política públicas y legislaciones a nivel local, nacional, regional e internacional, para atender problemas derivados de la desigualdad social y las diferencias culturales; 2) la necesidad de redefinir el desarrollo y las políticas sociales desde la perspectiva de la diversidad cultural para hacer frente a la exclusión ${ }^{3}$.

La conflictividad derivada de las desigualdades y diferencias sociales se ha incorporado en las agendas de los gobiernos y de los organismos multilaterales, las organizaciones no gubernamentales y los organismos privados, esto ha sido producto de la resistencia, organización, movilización y lucha histórica de los actores sociales emergentes, a través de las cuales han logrado trascender e incidir en el ámbito público; en consecuencia las últimas dos décadas refieren una profusa normatividad al respecto destacan algunos de los últimos instrumentos aprobados en la ONU: la Declaración Universal sobre la Diversidad Cultural; la Convención Internacional sobre la Protección y Promoción de la Diversidad y de las Expresiones Culturales; y, la Declaración de las Naciones Unidas sobre los Derechos de los Pueblos Indígenas que se suman a una legislación específica sobre derechos relacionados con la diversidad cultural ${ }^{4}$. Aún cuando representan un avance importante se mantiene un déficit sobre el reconocimiento de los derechos relacionados con la diversidad, no obstante, el mayor déficit se encuentra en la práctica, no basta contar con una legislación que reconozca, proteja y valore la diversidad, la gran tarea pendiente es cómo llevar a la práctica esos postulados en sociedades regidas bajo un principio organizador universal y basadas en relaciones asimétricas, discriminatorias y excluyentes.

En el ámbito institucional, de manera paralela a la elaboración de la legislación y el diseño de las políticas públicas, particularmente las de corte social, se ha desarrollado la definición de un entramado de nociones a partir de las cuales, las instituciones hacen suyas las demandas de los diversos actores sociales. Esta apropiación discursiva ha derivado en la puesta en marcha de políticas culturales para los pueblos indígenas, en momentos históricos específicos, como respuesta a las demandas sociales y con la finalidad de disminuir la conflictividad; en esta dinámica, los proyectos para la atención de la diversidad parten de la idea de 'llenar' vacíos, bajo supuestos o categorías residuales

\section{Maracanan}


encriptadas en el discurso. En consecuencia, tanto en la academia como en la práctica, corresponde generar cuestionamientos que contribuyan a desmontar las políticas, los procesos cotidianos y los mecanismos subcutáneos del poder, con una mirada histórica más abarcadora, lo cual no implica extender el análisis sino identificar los diferentes enfoques para tomar distancia de las concepciones estrechas e instrumentales con la finalidad de ponerlas en el centro del debate hacia la significación de las categorías para transformar las relaciones y las prácticas.

Actualmente, el concepto diversidad cultural está en debate y construcción, con relación a este concepto se establecen de manera general dos vertientes: en el marco de las políticas públicas la emergencia de los nuevos actores y la cada vez más 'visible' diversidad cultural se percibe como un fenómeno que ha fragmentado la estructura y obstaculiza la 'recomposición' del tejido social y el desarrollo económico; en este sentido se plantea la política de atención a la diversidad, en la que subyace la idea de que esta situación es excepcional, transitoria y deberá superarse. En la perspectiva de los actores sociales emergentes, la diversidad se considera como una posibilidad y fortaleza para enriquecer las relaciones y los intercambios en la sociedad, es en esta lógica que la organización y resistencia se moviliza hacia la necesidad de incidir en los espacios públicos y en la toma de decisiones, con base en el diálogo como sustento de relaciones y prácticas sociales inclusivas porque la diversidad es consustancial a la sociedad, es un rasgo permanente de la vida social humana que refiere la coexistencia de sistemas culturales distintos cuya relación se ha conformado a través de la historia, una historia de negación y menosprecio de una cultura hacia la otra.

\section{Políticas Culturales y Derechos Ciudadanos}

Actualmente, la cartografía de los actores sociales en América Latina es difusa y el sistema mundo se fragmenta; esta situación tiene su referencia inmediata en el concepto de ciudadanía, en la perspectiva del estado liberal que presupone igualdad de acceso a las oportunidades, no solo en términos materiales y económicos, sino también simbólicos. En esta visión subyace una base de desigualdad y de exclusión; el concepto se relaciona con la igualdad en el marco de los derechos universales, pero a su vez se subordinan las 
diferencias; no se reconoce la emergencia de nuevas identidades y de otras formas de participación y representación política. El discurso de la ciudadanía no puede sostenerse sobre la base de la igualdad de derechos porque es necesario reconocer desigualdades materiales, simbólicas, culturales, raciales. La igualdad ciudadana tiene como fondo una marcada exclusión, punto de origen de los movimientos que luchan por el reconocimiento de las diferencias de género, de raza, preferencia sexual, adscripción religiosa, etc., a través de los derechos humanos que son el producto de movimientos sociales que forman una nueva cultura política a los cuales se suman los movimientos que se originan por la desigualdad económica, social, política y diferencias culturales ${ }^{5}$.

El concepto y el ejercicio de la ciudadanía al no reconocer la desigualdad, la afirma. La única posibilidad de reconocer los derechos, de promover la tolerancia y el respeto, es reconocer las desigualdades y las diferencias. En el caso de la educación sirva de ejemplo, la escolarización socialmente obligatoria encaminada a garantizar el 'desarrollo social' no implica necesariamente inclusión; porque en el marco de una educación 'nacional' con un enfoque único deriva en exclusión social y cultural. Por otro lado, no es lo mismo la demanda por escolaridad que demanda por conocimiento, como distinta es la exclusión cultural que la exclusión de bienes materiales, es decir, los seres humanos somos diferentes lo cual no es inherente a la desigualdad de derechos de carácter jurídico.

Los derechos ciudadanos son de carácter individual; los derechos sobre la diversidad cultural refieren al reconocimiento de los derechos de movimientos y actores sociales y colectivos; su organización, resistencia y lucha se centra en los sujetos colectivos; en esta lógica es impostergable el rediseño de mapas culturales de los actores sociales de los movimientos emergentes, de manera que tengan presencia e interlocución en el Estado.

Porque:

La representación de grupo institucionaliza mejor la justicia en circunstancias de dominio y opresión social. Pero también maximiza el conocimiento expresado en la discusión, por lo que promueve la sabiduría práctica. Las diferencias grupales no sólo implican necesidades, intereses y objetivos diferentes más importantes a partir de los cuales se comprenden las políticas y hechos sociales, 1996$)^{6}$.

\section{Maracanan}


No se cuestionaban anteriormente, los mensajes emitidos por el Estado a través de la educación y las instituciones culturales; básicamente, lo que se ponía en duda era su eficacia y su eficiencia; así, en las últimas décadas se ha puesto en tela de juicio el proyecto de nación, el cual está más interesado en ocultar las diferencias culturales y las desigualdades sociales en tanto las reproducen a través de sus políticas culturales y sociales. Las políticas culturales conllevan a una construcción social de la cultura nacional inmersa en el conflicto y la desigualdad; construcción en la cual hay una valoración selectiva del repertorio cultural acorde a intereses y proyectos específicos, que van de las condiciones de subordinación hasta el avasallamiento cultural.

La cultura dominante elabora una concepción de la sociedad en la perspectiva del poder y la dominación. Es una concepción que busca imponerse tal y como ha sucedido en los procesos coloniales en el tiempo. La cultura occidental ha pretendido instaurarse como cultura universal, con ello se imponen esquemas de valores que se aplican a la conformación de la llamada cultura nacional la cual, a su vez, soslaya la diversidad cultural existente; no existe una cultura común, existen diversas culturas propias de los pueblos indios, grupos sociales, comunidades humanas.

Esto es

...una heterogeneidad propiamente comunicativa: de mundos de vida, de tradiciones y constelaciones simbólicas que los rigen, de sus orientaciones disímiles y múltiples inarticulaciones, todo lo cual impide pensar a la sociedad y su cultura como una unidad, como una totalidad, y fuerza a un reconocimiento fragmentario, a síntesis conceptuales nunca logradas, en fin a la "insoportable levedad" de las palabras y los discursos que intentan perforar esa heterogeneidad?.

Pretender una cultura común a todos significa despojar a los grupos culturales de su iniciativa y de su creatividad; significa convertirlos en consumidores y no en creadores de cultura. La cultura hegemónica, base de la legitimidad del Estado y el consenso impone y expropia donde las políticas nacionales impulsan determinada cultura o rasgos de algunas culturas o, bien, promueven su destrucción. La imposición de un modelo cultural de desarrollo civilizatorio destruye tecnologías y saberes locales. La ausencia de

Janeiro | Dezembro 2011 
instancias de participación democrática en la definición de políticas e instituciones culturales donde las culturas y grupos subordinados sean reconocidos y puedan expresarse, genera conflictos. El poder tiene un fuerte impacto en las culturas, y en el contexto del Estado - nación porque se reconoce 'una' cultura, entendida como sinónimo de la cultura universal en la que se inscribe el proyecto nacional. Esta concepción suma a la diversidad, la desigualdad, porque las culturas son distintas y desiguales.

\section{Los Derechos de Los Pueblos Indígenas}

La movilización de los pueblos indígenas, con relación a sus demandas históricas, en los últimos treinta años fue paralela y acompañada de actores cuyas demandas están relacionadas con la diversidad cultural. Estos eventos se convirtieron en objeto de estudio por parte de la academia, estos esfuerzos derivaron en investigaciones de frontera de corte interdisciplinar, entre ellos destacan los logros, pendientes sobre el compromiso para garantizar el ejercicio de los derechos, la administración y el acceso a la justicia, con base en el análisis positivo y afirmativo de los derechos de los pueblos indios en la concepción y aplicación de los instrumentos internacionales jurídicos y políticos. Sin embargo, el sistema de justicia de los gobiernos latinoamericanos, de manera general, hace caso omiso de las recomendaciones emitidas por instancias nacionales e internacionales de derechos humanos y bajo esta lógica la administración de justicia y ejercicio de los derechos no están garantizados para los pueblos indígenas.

En el presente se manifiesta una tendencia hacia la criminalización de la protesta y la diferencia. La expresión de las demandas y la manifestación pública son caracterizadas como delitos graves. Hoy, la seguridad nacional se ha convertido en el 'propósito' más valorado por los gobiernos, dispuestos a pasar por encima de la incipiente democracia latinoamericana, restringiendo las libertades y los derechos a cambio de seguridad, ofrecen 'protección', niegan el ejercicio de los derechos humanos, sociales, políticos, económicos y culturales, éstos son la moneda de cambio.

Y para que ello sea así, los orígenes de la opacidad deben estar empotrados en cuestiones lo suficientemente obvias, naturalizadas y antiguas, para que seamos tan incapaces de cuestionarlas diariamente.

\section{Maracanan}


Voy a plantear brevemente las cuestiones sobre las que me estoy preguntando, y en torno de las que está organizado este trabajo. En primer lugar, me interesa vincular el poder de policía - como técnica administrativa de gobierno- con las formas vernáculas de su ejercicio. En segundo lugar, establecer el parentesco entre esas técnicas policiales y la expansión de Estados de excepción, como formas habituales de conjurar la inseguridad, reproduciendo paradójicamente el miedo ${ }^{8}$.

Ley patriota ${ }^{9}$ para enfrentar el terrorismo. Es no sólo es discurso, sino la estrategia adoptada por las autoridades de la región que criminaliza la movilización social y la protesta al tipificarla como delito. Y para que ello sea así, los orígenes de la opacidad deben estar empotrados en cuestiones lo suficientemente obvias, naturalizadas y antiguas, para que seamos tan incapaces de cuestionarlas diariamente.

Voy a plantear brevemente las cuestiones sobre las que me estoy preguntando, y en torno de las se realiza la disertación en este texto. En primer lugar, interesa vincular el poder de policía -como técnica administrativa de gobierno- con las formas vernáculas de su ejercicio. En segundo lugar, establecer el parentesco entre esas técnicas policiales y la expansión de Estados de excepción, como formas habituales de conjurar la inseguridad, reproduciendo paradójicamente el miedo ${ }^{10}$.

En este contexto se crea un ambiente en el que el ejercicio de los derechos y el acceso a la justicia es cada vez más difícil.

La debilidad estatal se expresa cada vez más en la pérdida del monopolio de la fuerza. Esto, por supuesto, debilita el imperio de la ley. Todo ello en un marco en el cual el Estado es incapaz de asegurar a toda la población el acceso a los bienes públicos básicos ${ }^{11}$.

Este es el escenario en el cual se demanda y lucha por el ejercicio de los derechos humanos en particular de los derechos de los pueblos indígenas. Resulta complejo hacer realidad los derechos de las personas, porque los derechos se cumplen, a medida que las sociedades se van desarrollando y la efectividad del ejercicio de los mismos es más viable.

En el marco de las 'nuevas amenazas' la tipificación de los delitos es ambigua y laxa, allí donde el arbitrio se convierte en la arbitrariedad y pasa por 
alto los derechos humanos y sociales de las personas, hace vulnerables a los movimientos sociales y las formas de resistencia.

\section{Los Derechos de los Pueblos Indios en el Marco de la Ciudadanía}

Los derechos humanos fueron constituidos por la cultura hegemónica; hoy, estos derechos se transgreden en forma sistemática o simplemente no se cumplen. Hay tareas sociales fundamentales pendientes para revertir la desigualdad y la exclusión que se vean reflejadas en el establecimiento de relaciones sociales, económicas, políticas y culturales diferentes; relaciones cuya base deberá ser la tolerancia y el respeto desde una perspectiva incluyente.

La internacionalización de los conflictos y las tensiones entre los pueblos indios y las sociedades nacionales pone en el centro de la discusión la legitimidad del Estado y el gobierno así como el peligro de la unidad de la nación. A lo largo de la historia las élites dominantes han impuesto y extendido su hegemonía sobre el resto de la población, esto ha llevado a la confrontación entre las llamadas mayorías y minorías que deriva en relaciones entre dominantes/subordinados mediante el uso del poder y los recursos del Estado. Los pueblos indios se movilizan políticamente en la búsqueda de interlocución con el Estado en el marco del principio político mayoritario, el nacionalismo dominante lo percibe como una amenaza desestabilizadora hacia un sistema políticamente organizado ante el cual estos pueblos no se identifican, no están representados y están excluidos. Aún cuando los Estados reconocen su carácter pluriétnico en los hechos existe un reclamo para transitar del discurso a los hechos porque en el contexto de los estados con gobierno democráticos de corte liberal la presión se dirige hacia la construcción de una nación homogénea con base en elementos como una ciudadanía común (territorial y cívica); criterios étnicos, atributos culturalmente compartidos como idioma, religión, ascendencia común; pertenencia, identidad cultural; patria e historia para la unificación ${ }^{12}$.

En el contexto de la globalización y de la economía internacionalizada, el Estado está acotado al mercado, se muestra incapaz de satisfacer las necesidades identitarias de numerosas poblaciones, de manera paralela los actores emergentes se han posicionado en el espacio público y han cobrado mayor conciencia transitando del espacio de conflicto y tensión hacia la disputa por

\section{Maracanan}


sus derechos en el contexto de los Estados nacionales espacio en el que son marginados y excluidos debido a sus diferencias culturales ${ }^{13}$.

La diversidad cultural en sí misma no genera conflicto, éste se ha desarrollado a lo largo del proceso histórico desde la colonización, gestándose posturas racistas y xenófobas en tanto se lucha por derechos colectivos, identidades locales, regionales o comunitarias. El marco liberal de los Derechos Humanos Universales es un ingrediente necesario para el reconocimiento de la igualdad y la dignidad de las personas, las tensiones se manifiestan entre las identidades culturales y la ciudadanía, porque los procesos de desarrollo y modernización son el escenario de los conflictos entre las sociedades nacionales y los pueblos indios, éstos últimos vistos como la imagen viva del atraso.

En el presente, la incorporación de los derechos de los pueblos indios en las legislaciones, paradójicamente presenta nuevas complicaciones porque no es lo mismos plantear demandas a un Estado que quieres cambiar o modificar o a un Estado que supuestamente te representa con la ausencia de una base social.

Existe un desplazamiento y ruptura de los códigos liberales del derecho. Cuando se ha impuesto el valor de la democracia procedimental, todo lo codifica en términos de derechos y leyes para que se consagren las formas de gestionar las políticas públicas para intervenir en la vida social de los sujetos.

El paradigma liberal plantea un esquema de los derechos en el formato de las políticas públicas para forjar el pacto social. En esta tesitura deja de ser sólo una cuestión de derechos, está en juego la justicia la cual está vinculada con la multiforme participación en la convivencia.

El debate sobre la ciudadanía indígena ha derivado en la manifestación y participación de diferentes actores sobre la legitimidad de sus demandas, en el contexto de los derechos de los pueblos indios se reconoce a la educación como uno de los asuntos más importantes de la vida pública. Posicionar a la educación en un asunto público de primer orden fue una batalla liberal, hoy la lucha por la educación, el acceso universal y el financiamiento público es también por la igualdad, la libertad y la democracia en la región. Las constituciones han

Transformado las leyes que rigen la educación, en algunos casos se han dado cambios y en otros retrocesos.

El derecho indígena está conformado por un sistema de normas jurídicas o sistema de derecho que han sido incorporadas en las constituciones de la región 
recientemente. En términos generales, estas constituciones reconocen la conformación diversa y plural de nuestras sociedades, esto conlleva a determinar criterios de acceso a la justicia: el derecho a los juicios orales y la garantía del debido proceso, ambos representan igualdad ante la ley y en consecuencia el derecho a la disposición de los recursos necesarios para establecer en forma justa la sentencia sobre la violación de los derechos humanos frente a un tribunal competente independiente e imparcial, que el juicio de celebre en un plazo razonable; derecho de defensa; traductor que conozca la lengua y cultura, entre otros -como lo estipula la Corte Interamericana de Derechos Humanos ${ }^{14}$.

En este sentido se hace necesario pensar a la gobernabilidad democrática como la ampliación y la profundización de la participación de actores sociales heterogéneos y colectivos en la toma de decisiones en los asuntos de estado; este escenario plantea la necesidad de definir en términos de lo posible, el concepto de nación, una entidad plural y heterogénea, base de la conformación de un estado plural con la capacidad jurídica de todos los habitantes en la concurrencia política. En la realidad histórico social actual - aunque en de manera restringida- se han abierto algunos espacios a la acción de sujetos colectivos y multiculturales, porque las organizaciones sociales dan estructura orgánica a un todo complejo en el que se gestionan las autonomías entendidas como la capacidad de decidir por ellas mismas ${ }^{15}$. Las culturas no solo son diversas sino también tienen diferente presencia y reconocimiento (poder); lo que algunos autores han caracterizado como culturas dominantes y culturas subalternas.

En este contexto, en el caso de los derechos de los pueblos indígenas el reconocimiento debe ser como sujeto de derecho y, el rechazo terminante, a que se rijan por el interés individual o de grupo; es decir, allí donde el sujeto de derecho sean los pueblos.

El futuro de una sociedad orgánicamente plural requiere que los protagonistas de los sistemas articulatorios se conozcan mejor, y que esa nueva relación esté libre de estereotipos ideológicos y prejuicios estigmatizantes adjudicados a la condición indígena. La creciente visibilidad política de los pueblos indios debe así estar acompañada por una mayor comprensión de las formas culturales singulares de las cuales son herederos, reproductores y productores. Ello significa revalorar el conocimiento etnográfico, no en términos de los inventarios descriptivos del pasado, sino como datos para la construcción de un inédito diálogo intercultural.

\section{Maracanan}


El ejercicio de los derechos implica reconstituir el ámbito de los derechos colectivos (y no como derecho de excepción) esto es, la gestión del pluralismo en donde tiene cabida la nación. La referencia apunta hacia la construcción histórica de un sujeto social colectivo.

En la noción de persona nos encontramos ante una categoría interna de las culturas, que proporciona a sus miembros un referente común basado en un mismo principio clasificatorio, que otorga un 'nosotros' compartido. En cambio la identidad étnica se manifiesta como una construcción ideológica, que sistematiza las representaciones colectivas derivadas de las relaciones interétnicas, las relaciones con los 'otros'16.

En esta perspectiva se valora el desempeño de los pueblos indios dentro de las redes sociales y simbólicas, propias de los distintos mundos culturales con los que interactúan. La visión occidental y la visión indígena en el plano operativo tienen mediaciones para articular las distintas visiones, probablemente el hecho jurídico no llegó pero el hecho político que ya estaba,

... los grupos étnicos subordinados se articulan en torno a reivindicaciones especificas que tienden a demandar cambios institucionales $y / 0$ constitucionales al Estado, $y$, en algunos casos plantean serios cuestionamientos a su legitimidad ${ }^{17}$.

Con el propósito de instaurar un régimen de justicia social solidario y humano. Diversas perspectivas han reducido el análisis de los pueblos indios al elemento problemático por excelencia en viejos y nuevos melting pots, o bien a un instrumento del juego competitivo favorecido por la estrategia de la 'ingeniería social'. Otros se han volcado hacia una perspectiva primordialista y otros más en la concepción del otro como esencialmente diferente, esto ha llevado a la legitimación del multiculturalismo.

Este es un punto de partida sustancial que tiene ingerencia directa en la manera en que se elaboran mudos conceptuales, en las modalidades de percepción, observación, interpretación y explicación frente al sujeto social de estudio. El problema de las alteridades sociales es uno de los ejes alrededor de los cuales giran estas diferentes percepciones ${ }^{18}$.

Los pactos sociales se establecen de manera conflictiva, los niveles de tensión y disputa están en función del contexto y la relación de fuerzas. Por ejemplo, la capacidad de los pueblos indígenas de controlar su territorio, 
decidir por ellos mismos y mantener el tejido social se politiza con la finalidad de que el estado pueda intervenir en el asunto de carácter público que representa un 'peligro' para la élite dominante.

La ficción de la nación tiene sus límites, pero opera jurídicamente. Frente a indígenas belicosos, el estado federal mexicano se niega a suscribir tratados por razón de la nacionalidad, por el argumento expreso de que tal cosa no cabe con ciudadanos propios, por el razonamiento explícito de que las tribus indias no pueden actuar como naciones, pero la necesidad obliga a hacerlo tanto a la federación como a los estados afectados. La premisa no pierde por ello su valor. Los tratados no serán tratados; no recibirán esta consideración jurídica. Tal cosa no cabía. Constituirán, mientras que fueran necesarios, compromisos políticos sin valor normativo alguno, ni siquiera rango legislativo y así también reservado al poder propio. (Clavero, 1994) ${ }^{19}$

\section{Apuntes para continuar el debate}

En el presente, el nudo del debate está en el reconocimiento de la diversidad sociocultural existente; en el sentido de que las sociedades liberales han desarrollado procesos simultáneos de asimilación- segregación con la tendencia a conformar una cultura homogénea, de la 'integración' nacional a través de cultura, historia, lengua, creencias, valores, identidad y pautas de conducta comunes. La historia social refiere que ciertas minorías quedaron al margen del proceso, ya sea por estrategias excluyentes o aislacionistas atravesadas por diferencias culturales, a las cuales se suma la condición socioeconómica; a su vez, la marginación se asocia a la reducción o ausencia de los derechos ciudadanos para las minorías o sectores de la población minorizados (en algunos países latinoamericanos, es el caso de los pueblos indígenas). Un paradigma único no puede construirse como legítimo cuando excluye la particularidad; en el marco del derecho liberal se reivindican particularidades propias y opciones de conversión como principios universales; la particularidad se presenta como universalidad y excluye otras opciones hacia la universalidad. Cuando los principios particulares se han universalizado son impuestos y tienden a su 'naturalización' e influencia en el mundo del pensamiento y de las instituciones, sin embargo, hoy las perspectivas universalistas manifiestan dificultad para adaptarse a la pluralidad de nuestras sociedades.

\section{Maracanan}


Las Constituciones latinoamericanas en el marco de los 'nuevos derechos' han realizado, en el discurso y en términos generales, la positivización de los derechos indígenas bajo el código liberal. En el presente en la Constitución Boliviana, por ejemplo, los derechos se reconocen como fin y función que asiste a e toda persona, en Ecuador como garantía de igualdad, en Venezuela como deber social y gubernamental, en Brasil como fundamento de la actividad pública. En algunos rubros de hace la diferenciación entre derechos humanos y derechos sociales; en otros casos se hace la acotación entre interés público, individual y corporativo.

Unos estados deciden que existen derechos indígenas específicos; otros, que no, o no deciden nada, lo que viene a ser lo mismo. ¿Hay igualdad de derechos entre indígenas? Y dentro de las fronteras del Estado que admite estos derechos, ¿hay igualdad entre indígenas y no indígenas? Si la consideración es de minoría, si los derechos especiales se adjudican con fin a una promoción integradora, puede predicarse la igualdad como principio y objetivo, como canon institucional. Pero, ¿y si el reconocimiento llega a ser como derecho propiamente colectivo? En el caso más claro y factible de disposición de cultura y territorio propios para un tal reconocimiento, el resultado es entonces que la propia comunidad indígena pasa a ser agente definidor de derechos dentro de ámbito.

Hoy día en la academia se debate el significado de conceptos tales como; pluralismo, multiculturalismo, interculturalismo, tolerancia, respeto, cultura, democracia, ciudadanía, asimilación, segregación, exclusión, integración, exclusión; y, un etcétera muy largo; no obstante la emergencia de la sociedad civil y la ciudadanía multicultural se están haciendo cargo de darles contenido. Un concepto más 'cercano' al contexto nuestro americano es el de pluralismo, que en términos de Villoro plantea el diálogo cultural y la unidad en la diversidad sin hacer necesaria la síntesis.

Hoy, es insoslayable hacer un lado la idealización de los pueblos indígenas y de las relaciones sociales, es preciso reconocer la unidad en contextos multiculturales en los que se genera tensión, conflicto y disputa para gestionar el reconocimiento y el respeto de la diversidad cultural. La expectativa va más allá del establecimiento de protocolos interculturales que plantea la política pública y culturiza las políticas sociales; es imperativo dar paso al ejercicio de los derechos culturales y no continuar culturizando los derechos. 
Los movimientos identitarios y sociales ponen en cuestión los principios políticos, éticos y epistémicos de la actuación estatal, en particular, de los pueblos indios, lo que plantean como proyecto la transformación estructural de la sociedad y para toda la población, por ello puede decirse que no es una propuesta étnica. Así, la perspectiva de establecer relaciones interculturales, de transformar las estructuras actuales tendiente a establecer relaciones horizontales, interétnicas, puede decirse que en las relaciones de poder, de saber, de ser y de vivir tienen un carácter distinto a la interculturalidad, la cual no existe, sino que es algo por construir en lo cotidiano. 


\section{Notas e Referências}

1 Carlos MONSIVÁis. A ustedes les consta. Antología de la crónica en México. México: Ed. Era, $4^{\circ}$ reimp., 1989. Serie Crónicas.

2 Héctor DÍAZ-POLANCO. Elogio de la diversidad. Globalización, multiculturalismo y etnofagia. México: Siglo XXI, 2006.

3 Aldo PANFICHI. Sociedad civil, esfera pública y democratización en América Latina: Andes y Cono Sur. México: Pontificia Universidad Católica del Perú/FCE, 2002.

4 ONU. Declaración de las Naciones Unidas sobre los Derechos de los Pueblos Indígenas. ONU, 2007. http:www.unic.or.ar/pag_esp/esp_pob-indigenas/ archivos/q\&a.pdf; Convención Internacional sobre la Protección y Promoción de la Diversidad y de las Expresiones Culturales. ONU, 2005. http://unesdoc. unesco.org/images/0014/001429/142919s.pdf; Declaración Universal sobre la Diversidad Cultural. ONU, 2001 http://portal.unesco.org/es/ev.phpURL

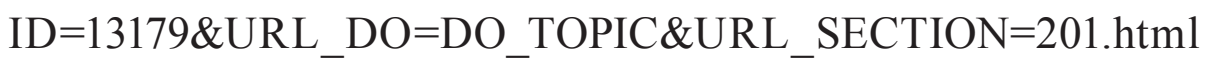

5 José Mauricio DOMINGUES. "Os movimentos sociais latino-americanos: características e potencialidades". Análise de Conjuntura OPSA, no. 2. Brasil. Fevereiro, 2007.

6 Carme CASTELLS. "Vida política y diferencia de grupo: una crítica del ideal de ciudadanía universal”. Perspectivas feministas en teoría política. Barcelona: Ed. Paidós. Estado y Sociedad N 43, 1996.

7 José Joaquín BRUNNER. América Latina: cultura y modernidad. México: CNCA/Grijalbo, 1988.

8 Alain P. LECOURS. (s/a) Ley Patriota. http://ponce.inter.edu/cai/bv/LEYPATRIOTA-DE-LOS-EE-UU-USA-PATRIOT-ACT.pdf.

9 Esta ley tiene efectos extraterritoriales al aumentar sustancialmente las facultades de las autoridades norteamericanas (FBI, CIA, NSA, y las fuerzas armadas norteamericanas) a efecto de obtener información confidencial, aún cuando violente las leyes de otros países. Como una medida que permitiría proteger la seguridad de la población norteamericana, al desenmascarar a terroristas internacionales, como consecuencia de los ataques terroristas del 11 de septiembre. Cfr. http://ponce.inter.edu/cai/bv/LEY-PATRIOTADE-LOS-EE-UU-USA-PATRIOT-ACT.pdf

10 Sofía TISCORNIA. "Entre el imperio del 'Estado de policía' y los límites del derecho". Nueva Sociedad, 191, Mayo-Junio, 2004, p. 80. 
11 Francisco ROJAS Aravena. "El riesgo de superposición entre las políticas de defensa y las de seguridad" In: Nueva Sociedad, 213, enero-febrero, 2008, http://www.nuso.org.

12 Rodolfo STAVENHAGEN. Conflictos étnicos y Estado nacional. México: Siglo XXI/Centro de Investigaciones Interdisciplinarias en Ciencias y Humanidades (UNAM)/ UNRISD, 2000.

13 Rodolfo StAVENHAGEN. La cuestión étnica. México: El Colegio de México, 2001.

14 COMISIÓN INTERAMERICANA DE DERECHOS HUMANOS. Convención Americana sobre Derechos Humanos. (Suscrita en San José de Costa Rica el 22 de noviembre de 1969, en la Conferencia Especializada Interamericana sobre Derechos Humanos) http://www.corteideh.oas.org/ Basicos/Basicos2.htm.

15 Pablo GONZÁLEZ Casanova e Marcos ROITMAN Rosenman. Democracia y estado multiétnico en América Latina. México: La Jornada Ediciones/Centro de Investigaciones Sociales, 1996.

16 Bartolomé CLAVERO. Derecho indígena y cultura constitucional en América. México: Ed. Siglo XXI, 1994.

17 Ana MARGOLIS "Vigencia de los conflictos étnicos en el mundo contemporáneo”. In:Estudios Sociológicos, COLMEX, Vol. X, ํ․ 28, enero-abril, 1992.

18 Susana DEVALLE. "La etnicidad y sus representaciones: juego de espejos". Estudios Sociológicos, COLMEX, Vol. X, N²8, enero-abril, 1992.

19 Bartolomé CLAVERO. Op.cit. 